\title{
Antifungal potential of some collagen-based nanocomposites Against Candida lusitaniae
}

\author{
Dragomira S. Stoyanova ${ }^{1}$, Iliana A.Ivanova ${ }^{1 *}$, Anna Staneva ${ }^{2}$, Madalina Alby-Kaya ${ }^{3}$ and Todorka \\ G. Vladkova ${ }^{2}$ \\ ${ }^{1}$ Department of General and Industrial Microbiology, Sofia University, "St.KlimentOhridski",Bulgaria \\ ${ }^{2}$ Department of Polymer Engineering, University of ChemicalTechnology and Metallurgy, Sofia,Bulgaria \\ ${ }^{3}$ Collagen Section, INCPI, Bucharest, Romania
}

Received: November 08, 2016; Accepted: November 28, 2016; Published: December 02, 2016

*Corresponding author: Ivanova IA, PhD, Assoc. Professor, Dept.General and Industrial Microbiology, Faculty of Biology, Sofia University "St. KlimentOhridski",Bulgaria; Email: ilivanova@abv.bg

\begin{abstract}
The possible mechanism of action of different nanomaterials on pathogenic fungi, significant for medical practice is summarizedin this article. Furthermore, the antifungal action of different collagen based nanocomposites against Candida lusitaniae was evaluated and compared. Collagen-based biomaterials with antimicrobial activity are attractive candidates for wound dressing, tissue engineering, components of implantable devices, etc. One of the easiest and most effective ways among the large variety of known approaches to add antimicrobial activity of biomaterials is development of composites including antimicrobial agents. In this study RGO, Ag/RGO, Ag/ SiO2/RGO, ZnTi03, ZnTiO3/SiO2/RGO and Ag/ZnO/ZnTiO3were entrapped in a porous collagen matrix by sol-gel cryogen drying to preserve the native biological activity of the collagen. No chemical interactions were expected in the Collagen/antimicrobial compounds nanocomposites under these conditions.The nanocomposites were prepared in different ratios of the compounds.The formed sterile zones around the disc samples (diameter of $9.0 \mathrm{~mm}$; thickness of 3 $\mathrm{mm})$ were measured in $\mathrm{mm}( \pm 0.5)$. The representative of eukaryotic organisms Candida lusitaniae demonstrated high sensitivity with large sterile areas at some of the tested materials.
\end{abstract}

Key words: Pathogenic fungi; Collagen matrix; Nanoparticles; Zone of inhibition; RGO- Reduced Graphene oxide

\section{Introduction}

Nanoscience has been emerged as a powerful tool to develop new approaches in the field of designing new antimicrobial drugs. Antifungal potential of nanoparticles should be considered in two directions connected to the seriousness and relevance of the issues. On the one hand is the clinical significance of fungal strains as C.albicans, T.asahii, T.mentagrophytes, A.niger, representing a direct threat to human health, causing skin, eye and otherdiseases. On the other handthe nanotechnology could be an alternative to deal with massive losses caused by phytopathogenic fungi such as Phomadestructiva, Curvularialunata, Alternaria alternate,
Fusarium oxysporumetc. In striving to feed the increasing global population [1].

Candida albicans is the most common pathogenic fungus isolated in bloodstream infections in hospitalized patients, and candidiasis represents the fourth most common infection in United States hospitals, mostly due to the increasing numbers of immune- and medically-compromised patients. C. albicans has the ability to form biofilms and morphogenetic conversions between oval cells and hyphal morphologies contribute to biofilm development. Moreover, these attached communities of cells are surrounded by a protective exopolymeric matrix that effectively shelters Candida against the action of antifungals. Because of dismal outcomes, novel antifungal strategies, and in particular those targeting biofilms are urgently required. As fungi are eukaryotic, research and development of new antifungal agents is difficult due to the limited number of selective targets, also leading to toxicityto macro-organism [2].

Similar to Candida,Trichosporonasahii is an emerging fungal pathogen and exist in several growth forms in response to environmental conditions[3].T.asahii can invade the human body through implantable catheters, abraded skins, mucosa, or respiratory tract, causing systematic and fatal trichosporosis and also has shown drug resistance[4, 5,6].

Other important dermatophyte fungus is Trichophyton [7, 8]. Trichophyton rubrum (T. rubrum) is known to account for as many as $69.5 \%$ of all dermatophyte infections $[9,10,11,12]$.The results of antifungal activity reveal that the growth of T. rubrum was inhibited atconcentration of $10 \mu \mathrm{g} / \mathrm{ml} \mathrm{Ag-NPsalone.} \mathrm{In}$ combination tests, fluconazole $(20 \mu \mathrm{g} / \mathrm{ml})$ together with Ag-NPs $(2.5 \mu \mathrm{g} / \mathrm{ml})$ and griseofulvin $(0.4 \mu \mathrm{g} / \mathrm{ml})$ with Ag-NPs $(2.5 \mu \mathrm{g} /$ $\mathrm{ml}$ ) demonstrated increasing antifungal effects on T. rubrum [13].

The problem with ocular pathogenic fungi, which causes keratomycosis increase because they are responsible for vision 
loss in the developing world like China [14]. Clinical studies indicate that keratomycosis constitutes about $46.7 \%$ to $61.9 \%$ of all cases of suppurative keratitis inpatients. Filamentous fungi, mainly Fusarium spp. or Aspergillus spp., are the most frequently isolated fungi in keratomycosis and the most common ocular pathogenic fungi. Fluconazole has high bioavailability against Candida spp., but Fusarium spp. and Aspergillus spp. are resistant to it $[14,15$, and 16]. Other antifungal is Natamycin, but it penetrates the cornea and conjunctiva poorly and effective drug levels are not achieved in corneas with intact epithelium. The penetrationfor amphotericin B was negligibleafter topical application because it was poorly soluble in water [16]. According to Gao et al [17]. The activity of nano-silver against Fusarium spp.,Aspergillus spp., andAlternariaalternata was significantly superior to those ofnatamycin and fluconazole against ocular pathogenic fungi in vitro.Previous studies demonstrate significant antifungal activity of Nano-Ag, in an IC80 range of 1-7 $\mu \mathrm{g} / \mathrm{ml}$ against T. mentagrophytes and Candida species[18].

Candida spp. represent one of the most common fungal pathogens often causing hospital-acquired sepsis with an associated mortality rate of up to $40 \%$ [19].Little is known about the epidemiology of infection with $C$. lusitaniae[20, 21]. Candida lusitaniae was originally isolated from the intestinal contents of warm-blooded animals [22]. In humans, C. lusitaniae rarely causes opportunistic infections, although 13 cases involving various sites, including the kidneys, peritoneum, and blood stream, have been described [20,21, 22, 23, and 24]. This species of Candida is of special interest because of its innate resistance to amphotericin $\mathrm{B}$ and its ability to develop resistance to amphotericin during therapy [23, 25, and 26].A literaturereview [24] on C. lusitaniae infections update and better characterize the illness in the era of azole availability and standardized methodologies for antifungal susceptibility testing. In this review C. lusitaniae infection occurred in relatively young patients in a 55 cases (median age, 44 years). Fungemia was found in $80 \%$ of patients. Other infection syndromes, including peritonitis, meningitis, and urinary tract infection, were much less common [24].

Antimicrobial effect of silver nanoparticles (Ag-NPs) were investigated on manybacteriaandyeastmore than 60yearsalready, butthe mechanisms of action are still not fully understood [27]. The nanoparticles attack the respiratory chain, cell division and finally lead to cell death [28]. Silver also forms complexes with various DNA bases (adenine, guanine, cytosine and thymine) and is a potent inhibitor of fungal DNA ases and in the same time it could form complexes with electron donors containing Sulphur, oxygen or nitrogen (thiols, carboxylates, phosphates, hydroxyl, amines, imidazoles, indoles). The inhibition action of silver ions may include displacing of native metal cations from their usual binding sites in enzymes. The possible mechanism of action of Ag NPs has been suggested according to the morphological and structural changes in microbial cells. The Ag NPs show efficient antimicrobial properties that could be explained with their extremely large surface area, which provides better contact with microorganisms [29]. The antifungal activity of Ag NPs also includes damages of fungalsporesin nanocomposits with silica or organic material as pullulan [30,31]. Silver nanoparticles may inhibit the growth of $T$. asahii by permeating the fungal cell and damaging the cell wall and cellular components, in concentration of $4 \mu \mathrm{g} / \mathrm{ml}$. SEM Images have shown the deformed, distorted and shrunk and fracturedmycelium, with damaged surface, leading to the outflow of intracellular components and shrinkage of mycelium [31].

Zamperini et al [32]reporteda membrane depolarization of Candida albicans, an arrest of the fungal cell cycle by flow cytometry, release of intracellular glucose and trehalose, a decrease in plasma membrane fluorescence with increasing concentrations of Ag nanoparticles, pits in the cell wall, and pores in the plasma membrane on the TEM images. Other findings demonstrate that Ag nanoparticles destruct the fungal membrane integrity,dissipating the electrical potential of the membrane and inhibiting the normal budding process[33, 34].AgNPs inhibited the growth of $A$. flavus by affecting cellular functions which caused deformation in fungal hyphae, reduction in spores number, malformation and hypertrophy, leading to destruction and damage of spores [35].

C. albicans and C. tropicalis showed high sensitivity to AgNPs, Kim et al. shows the inhibition of C. albicans at $2 \mu \mathrm{g} /$ $\mathrm{ml}$ concentration of Ag-NPs[36].Other authors reports ten to 400 times higher concentrations, depend on their size and ways to obtainAg-NPs[18, 19, 37].The combination betweenfluconazoleand $\operatorname{AgNp}(32.5 \mathrm{~nm}$ average size spherical AgNp obtained by extracellular biosynthesis by the fungus Alternaria)showed the maximum inhibition against $C$. albicans, followed by Phomaglomerata and Trichoderma spp., whereas no significant enhancement of activity was found against Pleosporaherbarum and F. semitectum [38].

It was also determined that AgNp were more effective in reducing biofilm biomass when applied to adhered cells $(2 \mathrm{~h})$ than to pre-formed biofilms ( $48 \mathrm{~h}$ ), with the exception of C. glabrata, which in both cases showed a reduction of $\sim 90 \%$. AgNp were highly effective on adhered C. globate and respective biofilms. On C. albicans the effect was evident as a reduction in the number of viable biofilm cells. These results suggest that AgNp could be an effective alternative to conventional antifungal agents for therapies in Candida associated denture stomatitis [39].

AgNp at ultralow doses of $0.001 \%$ was effective against C. albicans, C. globate and M. sympodialis, yeast species often found in atopic dermatitis patients. Despite its 3.4-times lower silver content, the AgNp preparation exhibits an antimicrobial activity against the bacteria yeasts and dermatophytes tested, comparable to that of silver sulfadiazine at concentrations of $0.1 \%[40]$.

Li et al[41].evaluate the surface morphology change of the native and treated $C$. albicans and $C$. tropicalis with the prepared GO nanoparticles.After treatment with pure GO for $24 \mathrm{~h}$, the yeast cells were covered by a single layer wrinkled GO. After contact with carbon nanoscrolls/AgNPs, the yeast morphology significantly changed, with a major damage in cytoplasmic membrane of $C$. albicans, the content of the yeast cell leaked completely.The 
similar phenomena also can be seen in $C$. tropical is cells, as the ionic silver released, and a distinct concave could be observed on the cell membrane. When the $C$. tropical is cell was covered by a non-AgNPs content GO nanosheets the cell membrane kept relative integrity, but with GO/AgNPsthe membrane of the fungal cells collapsed apparently and the cytoplasm released partially [41].

The antimicrobial activity of zinc oxide nanoparticles (ZnONPs) is mainly due to generation of highly reactive species like $\mathrm{OH}^{-}, \mathrm{H}_{2} \mathrm{O}_{2}, \mathrm{O}_{2}{ }^{2-} . \mathrm{H}_{2} \mathrm{O}_{2}$ penetrates the cell and $\mathrm{OH}^{-}$and $\mathrm{O}_{2}{ }^{2-}$ damages the cell wall and cell membrane from outside [42]. The positive charged $\mathrm{ZnONps}$ were considered to have close physical interaction with fungal cells by direct electrostatic adsorption. As a result, cell membrane damage and cellular internalization were promoted [43]. The penetration of ZnONPs could cause more $\mathrm{ZnO}$-induced oxidative damage intracellular than outside the cells.A lot of studies have shown that ZnONPs induced the generation of ROS which cause oxidative stress $[42,43,44,45]$.Though excessive ROS-generation imposed unacceptable oxidative stress to cells that result in cell damage, small amount ROS can be tolerated by most cell types [44].ZnO NPs has a very good antifungal activity against different types of yeast including Candida spp, Trichosporonspp, Geotrichumsppand S. cerevisiae. The ZnO NPs were also effective against fluconazole resistant Candida isolates [46, 47, and 48].Candidalusitaniae is important nosocomial pathogen; it is acquired by indirect contact transmission between patients with transplantations and other immunocompromised patients in medical intensive care units $[21,49]$.

Sponge-like matrices show significant potential for the regeneration and repair of a broad range of damaged anisotropic tissues.The manipulation of the structure of collagen scaffolds using a freeze-drying technique is an intrinsically biocompatible way of tailoring the inner architecture of the scaffold[50]. The Collagen matrix impregnated with antibacterial agents is attractive candidates for wound dressing, tissue engineering, components of implantable devices, etc [51].

No reports about sensitivity of Candidalusitaniae to the nanocomposites of $\mathrm{ZnO}, \mathrm{ZnTiO}_{3}, \mathrm{RGO}$ and $\mathrm{Ag}$ in different ratio combinations with Collagentill now, which provoked us to conduct this investigation.

\section{Materials and methods}

\section{Preparation and characterization of RGO}

The used in this study RGO (with less that 2-3 w \% impurities of graphite materials) was prepared by commonly used chemical exfoliation method starting from purified natural graphite powder (99.9 \%, Alfa Aesar Co.) and employing sodium borohydride as a reducing agent, as it was described in [52].

The phase formation and structural transformation were detected by X-ray phase analysis (Bruker D8 Advance, Germany; $\mathrm{Cu} \mathrm{K} \alpha$; Lynx Eye detector).

\section{Preparation of Collagen/ RGO composites}

Type I fibril collagen gel with concentration of $2.64 \mathrm{wt}$. \% was extracted from calf hide using previously described technology [53]. The concentration of the collagen gel was adjusted at $1 \%$ and $\mathrm{pH}$ at 7.3 (that of the physiological medium) using $1 \mathrm{M}$ sodium hydroxide and antimicrobial agent (RGO powder) in 2:1, 2:0.8, 2:0.6, 2:0.4 or 2:0.2 ratios (wt/wt) was added. The in this way prepared collagen/antimicrobial agent composites were cross-linked with $0.5 \%$ glutaraldehyde (to dry collagen) at $4^{\circ} \mathrm{C}$ for $24 \mathrm{~h}$ and then lyophilized at $-40^{\circ} \mathrm{C}$ to obtain porous (sponge) material using a Martin Christ freeze-dryer for 48 hours, as it was previously described $[54,55]$. Test samples with diameter of $9 \mathrm{~mm}$ were prepared after that from each composite.RGO aggregates with different dimensions are wrapped in the collagen matrix, some of them partially covered by matrix collagen.The compressive modulus at $10 \%$ deformation was estimated of the studied Collagen/RGO composites, expecting that the presence of RGO could influence their mechanical strength [56].

\section{Antifungal activity tests}

In these study nanocomposites with compounds asRGO, $\mathrm{Ag} / \mathrm{RGO}, \mathrm{Ag} / \mathrm{SiO}_{2} / \mathrm{RGO}, \mathrm{ZnTiO}_{3} \mathrm{ZnTiO} / \mathrm{SiO}_{2} / \mathrm{RGO}$ and $\mathrm{Ag} /$ $\mathrm{ZnO} / \mathrm{ZnTiO}_{3}$ were impregnated in collagen matrix in different ratios and were examined as antifungal agent against Candida lusitaniae. The test fungal strain was obtained by National Bank of Industrial Microorganisms and Cell Cultures, propagated in YGS at $36^{\circ} \mathrm{C}$ and $120 \mathrm{rpm}$. At $12 \mathrm{~h}$ [57]. Microbial density of $0.5-0,8$ were determined according to McFarland. The aliquots of $100 \mu \mathrm{L}$ microbial suspension was randomly spread on solid medium (YGS agar) and discs of investigated material were put on them. The plates were left for $20 \mathrm{~h}$ at $4-6^{0} \mathrm{C}$ to afford diffusion of the nanoparticles and after that cultivated for $24 \mathrm{~h}$ at $36^{\circ} \mathrm{C}$. The formed sterile zones around the disks samples were measured in $\mathrm{mm}( \pm 0.5)$. Minimum two till 4 replicates for every composite were tested and mean values presented in the figures.

\section{Results and discussion}

The antifungal activity, as a sterile zone in $\mathrm{mm}$, of the studied antimicrobial agents loaded in collagen sponges is presented in Figures 1 to 6.

The used in this study RGO, consists of multilayer (up to 5) sheets with relatively large area (up to about $10 \times 20 \mu \mathrm{m}$ ) that tend to aggregate. They were dispersed in a collagen gel to be formed porous collagen/RGO composite after a cryogen drying, the last one keeping the native biological activity of the collagen. No chemical interactions between RGO and the collagen matrix were expected under these conditions. Aggregates of RGO sheets were wrapped in the collagen matrix, some of them partially coated by matrix collagen, as depicted by SEM images.

Although that the mechanism of the antimicrobial activity of RGO is not fully understood, it is generally accepted that it includesan effect of the direct cell membrane contact with sharp RGO nanosheets [58, 59]. In addition, destructive extraction of large amount phospholipids from E. coli cell membrane by graphene nanosheets (due to strong dispersion interactions between the RGO and the lipid molecules) is shown as a reason for the antibacterial activity of the graphene nanosheets [60]. 
In result of the test the antibacterial effect of RGO on the representative eukaryotic organisms Candida lusitaniae demonstrated high sensitivity with large sterile areas (data was shown in Figure 1) at themaximum tested concentration of RGO and small ones at the lowest of the tested concentrations. The high sensitivity of fungus is probably due to usage of nutrient medium with antibiotic Chloramphenicoland combination of

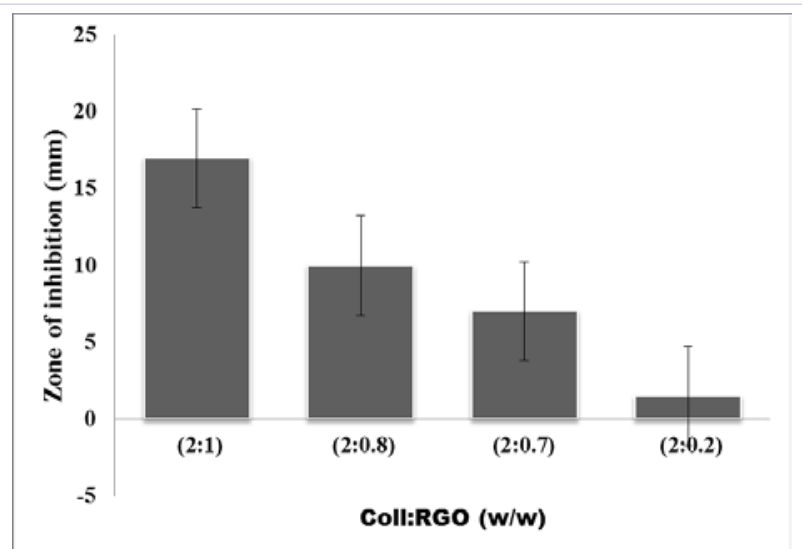

Figure 1: Antifungal effect of nanocomposite RGOin different weight ratio with collagen matrix - the size of the sterile zone around the disk. Antimicrobial effect of nanocomposites Ag/RGO in different ratios with collagen porous nanocompositescan is seen at Figure 2.Candida lusitaniae growth was inhibited of the all four different concentrations. The most pronounced results were obtained for the ratio 2:0,7and 2:0, 8. The antimicrobial effect of silver nanoparticles is well known $[2,7,8$, $13,18,30,31,33,34,35,62$, and 63 ]. Our result is interesting with the ratio of two compounds - the distribution of the silver nanoparticles was more uniformly at a ratio of Collagen: $\mathrm{Ag} / \mathrm{RGO}=2: 0.7$, were the highest activity was obtained. The lower antifungal activity of higher concentration could be due to agglomeration of active nano-Ag.

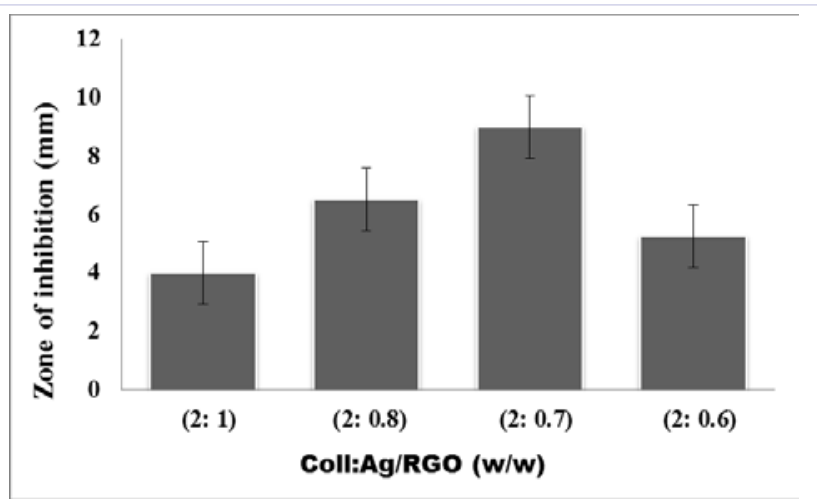

Figure 2: Antifungal effect of nanocompositeAg/RGO in different weight ratio with collagen matrix (the size of the disk is not included). In the case of Coll: $\mathrm{Ag} / \mathrm{SiO}_{2} / \mathrm{RGO}$ for $\mathrm{C}$. lusitaniae the strongest effect was observed for the highest concentration and three time weaker effect for the lower ratios. Data are shown in Figure 3. As other authors mentioned earlier dual action of nanocomposites combined with antibiotic have stronger antifungal effect [64].The results of synergistic action of nanoAg, $\mathrm{SiO}_{2}$ and $\mathrm{RGO}$ as a compounds of nanocomposite with collagen matrix were summarized and the data can be seen at Figure 3. The highest concentrations demonstrate significant effectiveness compared with other weight ratios

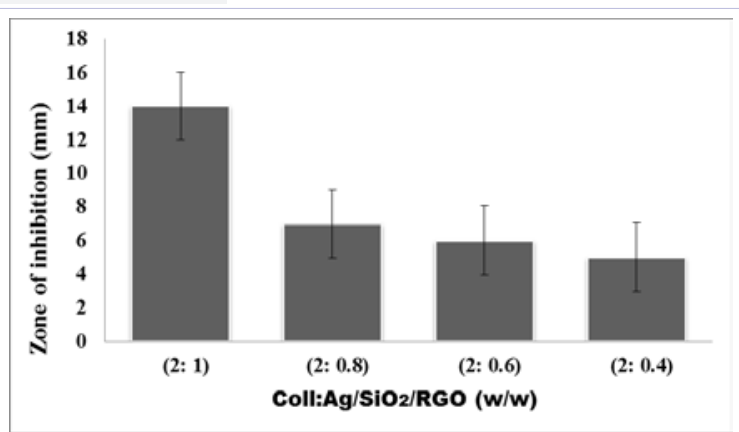

Figure 3: Antifungal effect of nanocompositeAg/ $\mathrm{SiO}_{2} / \mathrm{RGOin}$ different weight ratio with collagen matrix - the size of the sterile zone around the disk. Collagen/ZnTiO nanocomposite has shown antifungal activity at higher tested concentrationsagainst Candida lusitaniae.of Collagen: $\mathrm{ZnTiO}_{3}=2: 1$ (Figure 4). It is comparable to antifungal effect of Coll: Ag/ $\mathrm{SiO}_{2} / \mathrm{RGO}$, but the effect is more stable and does not reduce so quickly as that of to the Coll: $\mathrm{Ag} / \mathrm{SiO}_{2} / \mathrm{RGO}$ nanocomposite.

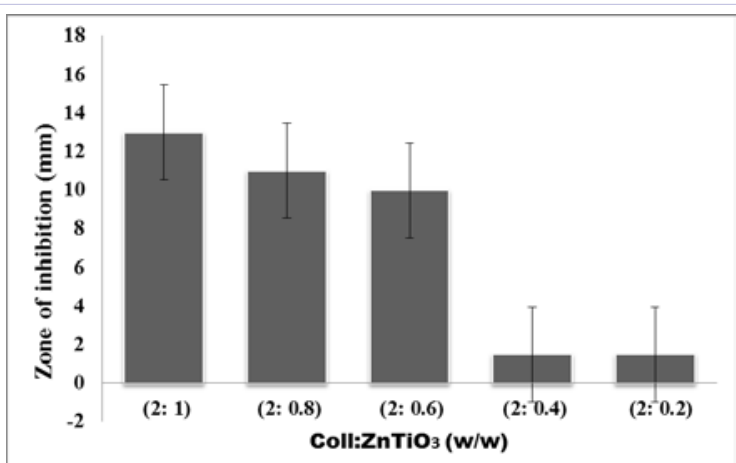

Figure 4: Antifungal effect of nanocomposite $\mathrm{ZnTiO}_{3}$ in different weight ratio with collagen matrix (the size of the disk is not included).In the contrast the highest antifungal effect of nanocompositeColl: $\mathrm{Ag} / \mathrm{ZnO} /$ $\mathrm{ZnTiO}$ was not at highest concentration of the active compounds to the collagẻn. The results may be due to agglomeration of nanoparticles. The results were illustrated at Figure 5.

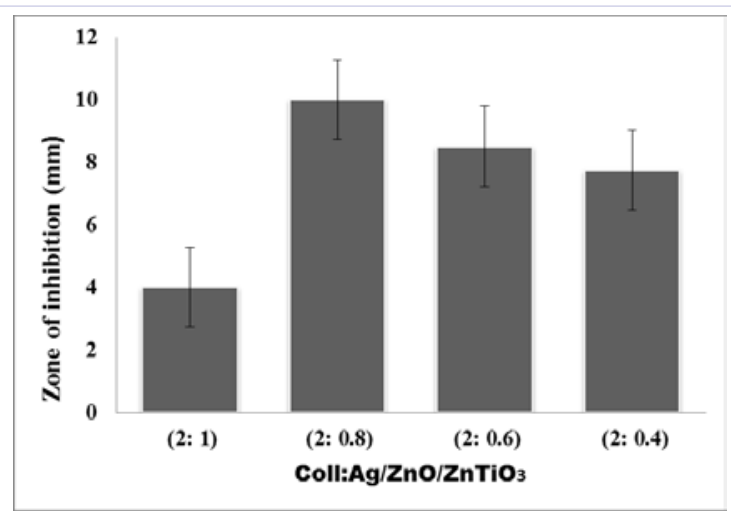

Figure 5: Antifungal effect of nanocomposite $\mathrm{Ag} / \mathrm{ZnO} / \mathrm{ZnTiO}$ in different weight ratio with collagen matrix (the size of the disk is ${ }^{3}$ not included). Antibacterial effect of nanocomposite $\mathrm{ZnTiO} / \mathrm{SiO}_{2} / \mathrm{RGO}$ on the tested fungal strain was the weakest by all tested nanomaterials as can be seen from Figure6. The result means possible gentle effect not only to the fungus, but also to the other eukaryotic cells and could be the aim of the further investigation. 




Figure 6: Antifungal effect of nanocomposite $\mathrm{ZnTiO} / \mathrm{SiO} / \mathrm{RGO}$ in different weight ratio with collagen matrix- the size of the sterile zone around the disk. The Coll:ZnTiO $/ \mathrm{SiO}_{2} / \mathrm{RGO}$ nanocomposite had insignificant inhibition effect on test microorganismCandida lusitaniae, butthe other examined materials have significantly higher antifungal effect. The most pronounced results were obtained for the ratio $2: 1$ at the most of the tested materials but Coll: $\mathrm{Ag} / \mathrm{ZnO} / \mathrm{ZnTiO}_{3}$ and Coll: Ag/RGOshow different results. The first is most effective at 2:0.8 and second nanocomposite at the ratio 2:0.7 respectively. If we compare effectiveness of the test nanomaterials, it can be concluded that the most effective against $C$. lusitaniae was Chloramphenicol in the nutrient medium in combination withhold: RGO (2:1) followed by Coll: Ag/ $\mathrm{SiO}_{2} / \mathrm{RGO}(2: 1)>$ Coll: $\mathrm{ZnTiO} 3$ (2:1)>Coll: $\mathrm{Ag} / \mathrm{ZnO} / \mathrm{ZnTiO}_{3}$ (2:0.8)>Coll: $\mathrm{Ag} / \mathrm{RGO}$ (2:0.7). Our results are comparable with these previously reported by other authors $[61,62,63,64]$. Strongest effect of Coll: Ag/ $\mathrm{SiO}_{2} / \mathrm{RGO}$ nanocomposite without antibiotic in nutrient medium was possibly due to the role of $\mathrm{SiO}_{2}$ as dispersing agent (vehiculum). It is important to mention that $\mathrm{SiO}_{2}$ alone as micro size powder has no antibacterial effect till the concentration of $6 \mathrm{mg} / \mathrm{ml}$ (results are not presented). Noble metals have proved their activity to bacteria and fungi [65], but the supported materials are also important for the obtained antimicrobial effects. As [66] reported, the level of susceptibility of $C$. lusitaniae to amphotericin B did not differ much from those of C. albicansand C. glabrata, so it could be suggest similar antifungal activity of tested nanocomposites to the other fungal pathogens.

both antimicrobial agents: antibiotic and nanosheets. Such kind of interaction is reported by [61, 62, and 63].

\section{Conclusion}

As a result of the current study it can be concluded, that the inhibition effects of the studied collagen-based nanocompositeson the fungal growth of $C$. lusitaniaedepends on the type of compoundsincluded in thenanocomposites and their concentration. The results from diffusion method in solid mediumindicate that some of the studied nanomaterials have strong pronounced effect on C.lusitaniaewhich are a close relative of the resistant to antibiotics Candida albicans. Thus we can say, that the studied collagen-based nanocomposites are promising anti-infective biomaterials.

\section{Acknowledgments}

Bulgarian Scientific Fund is acknowledged for the financial support of this investigation (grand DCOST 01/14 / 16.08.2016.) that is in the frame of COST Action TD1305 "Improved protection of medical devices against infections".

\section{References}

1. United Nations, World Population Prospects: The 2015 RevisionofWorld Population Prospects.

2. Lara HH, Romero-Urbina DG, Pierce C, Lopez-Ribot JL, ArellanoJiménez MJ, Jose-Yacaman M. Effect of silver nanoparticles on Candida albicans biofilms: an ultrastructural study. J Nanobiotechnology. 2015;13:91. doi: 10.1186/s12951-015-0147-8.

3. Kumar S, Bandyopadhyay M, Mondal S, Pal N. A rare case of nosocomial urinary tract infection due to Trichosporonasahii. J Glob Infect Dis. 2011;3(3):309-310. doi: 10.4103/0974-777X.83541.

4. Matsue K, Uryu H, Koseki M, Asada N, Takeuchi M. Break-through trichosporonosis in patients with hematologic malignancies receiving micafungin. Clin Infect Dis. 2006; 42(6):753-757. DOI: 10.1086/500323.

5. Biasoli MS, Carlson D, Chiganer GJ, Parodi R, Greca A, Tosello ME, et al. Systemic infection caused by Trichosporonasahii on patient with liver transplant. Med Mycol. 2008;46(7):719-723. doi: 10.1080/13693780802232928.

6. Gross JW, Kan VL. Trichsporon asahii infection in an advanced AIDS patient and literature review. AIDS. 2008;22(6):793-795. doi: 10.1097/QAD.0b013e3282f51ecc

7. Gajbhiye M, Kesharwani J, Ingle A, Gade A, Rai M. Fungus-mediated synthesis of silver nanoparticles and their activity against pathogenic fungi in combination with fluconazole. Nanomedicine: Nanotechnology, Biology, and Medicine. 2009;5(4):382-386. doi: 10.1016/j.nano.2009.06.005.

8. Panachec A, Kolar M, Vecerova R, Prucek R,Soukupová J, Kryštof $\mathrm{V}$, Hamal $\mathrm{P}$, et al. Antifungal activity of silver nanoparticles against Candida spp. Biomaterials. 2009 ;30(31):6333-6340. doi: 10.1016/j. biomaterials.2009.07.065.

9. Coloe SV, Baird RW. Dermatophyte infections in Melbourne: Trends from 1961/64 to 1995/96. Pathology. 1999;31(4):395-397.

10. Johnson RA. Dermatophyte infections in human immune deficiency virus (HIV) disease. J. Am. Acad. Dermatol. 2000;43(5):135-142.

11. Chen BK, Friedlander SF. Tinea capitis update: A continuing conflict with an old adversary. Curr. Opin. Pediatr. 2001;13(4):331- 335.

12. Chen WF, Wang JP, Zhuang GB. Treating fungal keratitis with natamycin. Ophthalmol. CHN.2000;9: 179-180.

13.Noorbakhsh F. Antifungal Effects of Silver Nanoparticle alone and with Combination of Antifungal Drug on Dermatophyte Pathogen Trichophyton Rubrum. International Conference on Bioscience, Biochemistry and Bioinformatics IPCBEE vol.5 (C) IACSIT Press, Singapore.2011.

14. Xuguang S, Zhixin W, Zhiqun W, Shiyun L, Ran L. Ocular fungal isolates and antifungal susceptibility in northern China. Am. J. Ophthalmol. 2007;143(1):131-133. DOI: 10.1016/j.ajo.2006.09.042

15. Xie, L.X. Fungal keratitis. Chin. J. Ophthalmol. 2003;39: 638-640.

16. O’Day DM, HeadWS, RobinsonRD, ClantonJA. Corneal penetration of topical amphotericin B and natamycin. Curr. Eye Res. 1986;5(11):877882 .

17. GaoC, Xu YY, Xu C. In Vitro Activity of nano-silver against Ocular Pathogenic Fungi. Life Sci J. 2012;9(4):750-753.

18. Kim KJ, Sung WS, Moon SK, Choi JS, Kim JG, Lee DG. Antifungal effect of silver nanoparticles on dermatophytes. J MicrobiolBiotechnol. 2008;18(8):1482-1484. 
19. Patterson, T.F. Treatment and prevention of fungal infections, Focus on Candidemia. Applied Clinical Education, New York. 2007.

20. Sanchez PJ, Cooper BH. Candida lusitaniae: sepsis and meningitis in a neonate. Pediatr. Infect. Dis. 1987;6(8):758-759.

21. Sanchez V, Vazquez JA, Barth-Joones D, Dembry L, SobelJD, ZervosMJ. Epidemiology of Nosocomial Acquisition of Candida lusitaniae. J Clinical Micobiol. 1992;30(11):3005-3008.

22. Van Uden N, Buckley H. Candida berkhout, In J. Lodder (ed.), The yeasts. A taxonomic study. North Holland Publishing Co., Amsterdam,1970.p. 893-1087.

23. Hadfield TJ, Smith MB, Winn RE, RinaldiMG, Ceuena C. Mycoses caused by Candida lusitaniae. Rev. Infect. Dis. 1987;9:1006-1012.

24. Hawkins JL, Baddoura LM. Candida lusitaniae Infections in the Era of Fluconazole Availability.Clinical Infectious Diseases, 2003;36 (2):e14-e18. DOI: 10.1086/344651.

25. Pappagianis D, Collins MS, Hector R, Remington J. Development of resistance to amphotericin B in Candida lusitaniae infecting a human. Antimicrob. Agents Chemother. 1979;16(2):123-126.

26. Blinkhorn RJ, Adelstein D, Spagnuolo PJ. Emergence of a new opportunistic pathogen, Candida lusitaniae. J. Clin. Microbiol. 1989;27(2):236-240

27. Franke S, Grass G, Nies DH. The product of the ybdE gene of the Escerichia coli chromosome is involved in detoxification of silver ions. Microbiol. 2001;147(4):965-972.

28. Rai M, Yadav A, Gade A. Silver nanoparticles as a new generation of microbials. Biotechnol. Adv. 2009;27(1):76-83. doi: 10.1016/j. biotechadv.2008.09.002.

29. Joen $\mathrm{H}, \mathrm{Yi} \mathrm{S}$, Oh S. Preparation and antibacterial effects of $\mathrm{Ag}_{-} \mathrm{SiO}_{2}$ thin films by sol-gel methods. Biomaterials. 2003;24(27):4921-4928.

30. Pinto R, Almedia A, Fernandes S, Freire C, Silvestre A, Neto C, et al. Antifungal activity of transparent nanocomposite thin films of pullulanand silver against Aspergillus niger. Colloids and surfaces B: Biointerfaces. 2013;103:143-148. doi: 10.1016/j. colsurfb.2012.09.045.

31.Xia Z-K, Ma Q-H, Li S-Y, Zhang De-Q, Cong L, Tian Y-L, et al. The antifungal effect of silver nanoparticles on Trichosporonasahii. Journal of Microbiology, Immunology and Infection, 2016;49(2):182-188. doi: 10.1016/j.jmii.2014.04.013.

32. C. A. Zamperini, R. S. André, V. M. Longo, E. G. Mima, C. E. Vergani, A. L. Machado, et al. Antifungal Applications of Ag-Decorated Hydroxyapatite Nanoparticles. Journal of Nanomaterials. 2013.

33. Kim KJ, Sung WS, Suh BK, Moon SK, Choi JS, Kim JG, et al. Antifungal activity and mode of action of silver nano-particles on Candida albicans.Biometals. 2009;22(2):235-242.

34. Al-Othman MR, Abd El- Aziz ARM, Mahmoud MA, Eifan SA, El-Shiikh MS, Majrashi M. Application of silver nanoparticles as antifungal and antiaflatoxin B1 produced by Aspergillus flavus. Digest Journal of Nanomaterials and Biostructures. 2014;9(1):151 - 157.

35. Xu Y, Gao C, Li X, He Y, Zhou L, Pang G, et al. In VitroAntifungal Activity of Silver Nanoparticles Against Ocular Pathogenic Filamentous Fungi. J OculPharmacolTher. 2013 ;29(2):270-274. doi: 10.1089/ jop.2012.0155.

36. Kim KJ, Sung WS, Suh BK, Moon SK, Choi JS, Kim JG, et al. Antifungal activity and mode of action of silver nanoparticles on Candida albicans. Biometals. 2009;22(2):235-242. doi: 10.1007/s10534-008-9159-2.
37. Miyazaki T, Kohno S. Current recommendations and importance of antifungal stewardship for the management of invasive candidiasis. Expert Rev Anti Infect Ther. 2015;13(9):1171-1183. doi: 10.1586/14787210.2015.1058157.

38. Higa LH, Schilrreff P, Perez AP, Morilla MJ, Romero EL. The intervention of nanotechnology against epithelial fungal diseases. J.Biomater. Tissue Eng. 2013; 3(1):70-88(19).

39. Monteiro DR, Gorup LF, Silva S, Negri M, de Camargo ER, Oliveira R, et al. Silver colloidal nanoparticles: Antifungal effect against adhered cells and biofilms of Candida albicans and Candida glabrata biofouling. The Journal of Bioadhesion and Biofilm Research. 2011;27(7):711719. doi: 10.1080/08927014.2011.599101.

40. Brandt O, Mildner M, Egger AE, Groessl M, Rix U, Posch M, et al. Nanoscalic silver possesses broad-spectrum antimicrobial activities and exhibits fewer toxicological side effects than silver sulfadiazine. Nanomedicine. 2012;8(4):478-488. doi: 10.1016/j.nano.2011.07.005.

41. Li C, Wang X, Chen F, Zhang C, Zhi X, et al. The antifungal activity of graphene oxide-silver nanocomposites. Biomaterials. 2013;34(15):3882-3890. doi: 10.1016/j.biomaterials.2013.02.001.

42. AbdElhady MM. Preparation and characterization of chitosan/zinc oxide nanoparticles for imparting antimicrobial and UV protection to cotton fabric. Int. J. Carbohy. Chem. 2012.

43.Espitia PJP, SoaresNFF, CoimbraJSR, Andrade NJ, Cruz RS, Medeiros EAA. Zinc Oxide Nanoparticles: Synthesis, Antimicrobial Activity and Food Packaging Applications. Food Bioprecess. Tech. 2012;5(5):14471464.

44. Lipovsky A, Nitzan Y, Gedanken A, Lubart R. Antifungal activity of ZnO nanoparticles-the role of ROS mediated cell injury. Nanotechnology. 2011;22(10):105101. doi: 10.1088/0957-4484/22/10/105101.

45. Patra P, Mitra S, Debnath N, Goswami A. Biochemical-, Biophysical-, and Microarray-Based Antifungal Evaluation of the Buffer-Mediated Synthesized Nano Zinc Oxide: An in vivo and in vitro Toxicity Study. Langmuir. 2012 Dec 11;28(49):16966-16978. doi: 10.1021/ la304120k.

46. Al-Amoud G.A., Albarrag A.M., Ashour E. Mycology: Resistance and mechanisms of action of antifungals. Evaluation of antifungal activity of zinc oxide nanoparticles against fluconazole-susceptible andfluconazole-resistant clinical yeast isolates.

47. Lakshmanan VK, Raj M, Biswas R, Hiroshi T, Nair SV, Jayakumar R. et al. Evaluation of wound healing potential of $\beta$-chitin hydrogel/nano zinc oxide composite bandage.Pharm Res. 2013;30(2):523-537. doi: 10.1007/s11095-012-0898-y.

48. Khan MF, AnsariAH, Hameedullah M, Ahmad E, Husain FM, Zia Q, et al. Sol-gel synthesis of thorn-like $\mathrm{ZnO}$ nanoparticles endorsing mechanical stirring effect and their antimicrobial activities: Potential role as nano-antibiotics. Scientific Reports. 2016;6:27689. doi: 10.1038/srep27689.

49. McClenny NB, Fei H, Baron EJ, Gales AC, Houston A, Hollis RJ et al. Change in Colony Morphology of Candida lusitaniae in Associationwith Development of Amphotericin B Resistance. Antimicrobial Agents and Chemotherapy. 2002;46(5):1325-1328.

50. Davidenko N, Gibb T, Schuster C, Best SM, Campbell JJ, Watson CJ, et al. Biomimetic collagen scaffolds with anisotropic pore architecture. Acta Biomater. 2012;8(2):667-676. doi: 10.1016/j.actbio.2011.09.033.

51.Soenen SJ, Rivera-Gil P, Montenegro J-M, Parak WJ, De SmedtSC, Braeckmans K. Cellular toxicity of inorganic nanoparticles: Common aspects and guidelines for improved nanotoxicity evaluation. Nano Today. 2011;6(5):446-465. 
52. Shalaby A, Nihtianova D, Markov P, Staneva AD, Iordanova RS Dimitriev YB. Structural analysis of reduced graphene oxide by transmission electron microscopy. BulgChemComm. 2015;47(1):291295.

53. Albu M, Titurenku I, Vladkova T. Fibrillar Collagen/Bioactive Calcium Phosphate Silicate Glass-Ceramic Composites for Bone Tissue Engineering. Current Tissue Engineering. 2013;2(2): 119-132.

54. Albu, M.G. Collagen gels and matrices for biomedical applications. $1^{\text {st }}$ ed. Saarbrucken: Lambert Academic Publishing. 2011.

55. Albu MG, Deselnicu V, Ioannidis I, Deselnicu D, Chelaru C. Chemical functionalization and stabilization of type I collagen with organic tanning agents. Korean J Chem Eng. 2015;32(2): 354-361.

56. Albu MG, Ghica MV. Spongious collagen-minocycline delivery systems. Farmacia. 2015;63(1):20-25.

57. Kjumdzieva - Savova A.V., Kechlibarova L.I., Savov V.A., Nedeva T.S., Georgieva E.I. (1992) Dependence of Candida Lusitaniae 74-4 protoplast yield on the growth phase and nutrient medium type. Comptesrendus de l'Academiebulgare des Sciences, 45, 5:91-94.

58. AkhavanO, Chaderi E. Toxicity of graphene and graphene oxide nanowalls against bacteria. ACS Nano. 2010;4(10):5731-5736. doi: 10.1021/nn101390x.

59. Akhavan 0, Chaderi E, Esfandiar A. Wrapping bacteria by graphene nanosheets for isolation from environment, reactivation by sonication and inactivation by near-infrared irradiation. J Phys Chem B. 2011;115(19):6279-88. doi: 10.1021/jp200686k.

60. Tu Y, Lv M, Xiu P, Huynh T, Zhang M, Castelli M, et al. Destructive extraction of phospholipids from Escherichia coli membranes by graphene nanosheets. Nat. Nanotechnol. 2013;8(8):594-601. doi: 10.1038/nnano.2013.125.

61. Hari N, Thomas TK, Nair AJ. Comparative Study on the Synergistic Action of Differentially Synthesized Silver Nanoparticles with $\beta$-Cephem Antibiotics and Chloramphenicol.Journal of Nanoscience. 2014.

62. Kalita S, Devi B, Kandimalla R, Sharma KK, Sharma A, Kalita K, et al. Chloramphenicol encapsulated in poly- $\varepsilon$-caprolactone-pluronic composite: nanoparticles for treatment of MRSA-infected burn wounds. Int J Nanomedicine. 2015;10:2971-2984. doi: 10.2147/IJN. S75023.

63. Gannimani R, Ramesh M, Mtambo S, Pillay K, Soliman ME, Govender P. $\gamma$-Cyclodextrin capped silver nanoparticles for molecular recognition and enhancement of antibacterial activity of chloramphenicol. J org Biochem. 2016;157:15-24. doi: 10.1016/j.jinorgbio.2016.01.008.

64. Monteiro DR, Silva S, NegriM, Gorup LF, de Camargo ER, Oliveira R, et al. Antifungal activity of silver nanoparticles in combination with nystatin and chlorhexidine digluconate against Candida albicans and Candida glabrata biofilms. Mycoses. 2013;56(6):672-680. doi: 10.1111/myc.12093.

65. Chwalibog A, Sawosz E, Hotowy A, Szeliga J, Mitura S, Mitura K, et al. Visualization of interaction between inorganic nanoparticles and bacteria or fungi. International Journal of Nanomedicine. 2010;5(1):1085-1094. DOI: 10.2147/IJN.S13532.

66. Favel A, Michel-Nguyen A, Datry A, Challier S, Leclerc F, Chastin C, et al. Susceptibility of clinical isolates of Candida lusitaniae to five systemic antifungal agents. J AntimicrobChemoth. 2004;53(3):526-529. DOI: 10.1093/jac/dkh106. 